\title{
Article
}

\section{Pd Nanoparticles in a Supported Ionic Liquid Phase: Highly Stable Catalysts for Selective Acetylene Hydrogenation under Continuous-Flow Conditions}

Marina Ruta, Gabor Laurenczy, Paul J. Dyson, and Lioubov Kiwi-Minsker

J. Phys. Chem. C, 2008, 112 (46), 17814-17819• DOI: 10.1021/jp806603f • Publication Date (Web): 28 October 2008

\section{Downloaded from http://pubs.acs.org on February 12, 2009}

\section{More About This Article}

Additional resources and features associated with this article are available within the HTML version:

- $\quad$ Supporting Information

- $\quad$ Access to high resolution figures

- $\quad$ Links to articles and content related to this article

- Copyright permission to reproduce figures and/or text from this article

\section{View the Full Text HTML}




\title{
Pd Nanoparticles in a Supported Ionic Liquid Phase: Highly Stable Catalysts for Selective Acetylene Hydrogenation under Continuous-Flow Conditions
}

\author{
Marina Ruta, Gabor Laurenczy, Paul J. Dyson, and Lioubov Kiwi-Minsker* \\ Institut des Sciences et Ingénierie Chimiques, Ecole Polytechnique Fédérale de Lausanne (GGRC-ISIC-EPFL), \\ CH-1015 Lausanne, Switzerland
}

Received: July 25, 2008; Revised Manuscript Received: September 14, 2008

\begin{abstract}
Monodispersed $\mathrm{Pd}$ nanoparticles of 5 and $10 \mathrm{~nm}$ were obtained via reduction of $\mathrm{Pd}(\mathrm{acac})_{2}$ dissolved in ionic liquid (IL), $[\mathrm{bmim}]\left[\mathrm{PF}_{6}\right]$, or $[\mathrm{bmimOH}]\left[\mathrm{TF}_{2} \mathrm{~N}\right]$, supported on carbon nanofibers $(\mathrm{CNF})$ anchored to sintered metal fibers (SMF). Using [bmimOH] $\left[\mathrm{TF}_{2} \mathrm{~N}\right]$, the monodispersed Pd nanoparticles were synthesized by simple heating in the absence of an additional reducing agent. The supported ionic liquid phase Pd nanoparticles on the structured CNF/SMF composites were tested for the selective hydrogenation of acetylene to ethylene and showed excellent long-term stability. The IL cation-anion network surrounding the nanoparticles suppressed the formation of active-site ensembles, known to catalyze the oligomerization of acetylene, responsible for the catalyst deactivation. The reaction rate was controlled by the internal diffusion of the reactants through the IL phase. The solubility of acetylene and ethylene in $\left[\mathrm{bmim}^{2}\left[\mathrm{PF}_{6}\right]\right.$ was analyzed by NMR spectroscopy, which showed an order of magnitude difference. The lower solubility of ethylene compared to acetylene in the IL results in a high selectivity to ethylene, up to $85 \%$ at $150{ }^{\circ} \mathrm{C}$. The catalytic system also demonstrated high efficiency and long-term stability without any deactivation in ethylene-rich feed ( 2 vol \% of acetylene, $40 \mathrm{vol} \%$ of ethylene, $10 \mathrm{vol} \%$ of $\mathrm{H}_{2}$ in $\mathrm{Ar}$ ), and therefore, the system shows promise for industrial application.
\end{abstract}

\section{Introduction}

The selective hydrogenation of acetylene is an important industrial reaction related to large-scale ethylene polymerization, typically performed to remove acetylene impurities $(<3 \%)$ from the ethylene feedstock. ${ }^{1,2}$ For commercial applications, acetylene must be $<10 \mathrm{ppm}$ in the ethylene feedstock. Supported Pd catalysts are most widely used for this purpose ${ }^{1,3}$ and remain under intensive study, with the aim of further improving catalyst stability and selectivity. The main drawback of existing catalysts is deactivation due to acetylene oligomerization leading to polyolefin (green oil) which blocks the metal surface. ${ }^{4-7}$ Limited selectivity and long-term stability of Pd-based catalysts is attributed to the formation of active-site ensembles; thus, they have to be avoided. Catalytic activity, selectivity, and stability strongly depend on the nature of the support and on the size of the Pd nanoparticles, because the hydrogenation of acetylene is a structure-sensitive reaction. ${ }^{8-11}$ The preparation of $\mathrm{Pd}$ nanoparticles with a narrow size distribution has therefore attracted considerable attention. However, nanoparticles need to be stabilized (by surfactants, block-copolymers, etc.) to avoid aggregation during the reaction, ${ }^{12}$ although the introduction of a stabilizer into the catalytic system affects catalyst performance. Recently, transition metal nanoparticles with narrow size distributions have been synthesized in imidazolium-based ionic liquids (IL) and applied to various multiphase catalytic processes. ${ }^{13-20}$ The IL acts as a template for the formation of nanoscale structures and stabilizes the metal nanoparticles by the formation of "protective" anionic and cationic layers. ${ }^{21}$ The stabilization of Pd nanoparticles by imidazolium-based ILs is very promising for the selective hydrogenation of acetylene, since the IL facilitates the control of the nanoparticle size. Moreover, the presence of the IL network around the Pd

* Corresponding author. Phone: +41-21-693 3182. Fax: +41-21-693 6190. E-mail: lioubov.kiwi-minsker@epfl.ch. nanoparticles creates supplementary diffusion resistance for reacting molecules and should suppress the formation of activesite ensembles. Nevertheless, for continuous-flow gas-phase reactions, the catalytic system should be heterogeneous. Therefore, the supported ionic liquid phase (SILP) concept seems suitable for this application. ${ }^{15,22-26}$ Recently, we demonstrated the successful use of SILP catalysts on structured supports consisting of carbon nanofibers (CNF) grown on sintered metal fibers (SMF) for gas-phase hydrogenations. ${ }^{27}$ The advantages of such a catalytic system emanate from a low pressure drop during the gas passage through the reactor and an even flow distribution as compared to randomly packed catalytic beds. Furthermore, the use of the CNF/SMF support ensures the homogeneity of the SILP layer and, due to the chemical inertness of CNF surface, no chemical interaction between the support and the SILP catalyst has been observed ${ }^{28}$ Herein, we report a study of Pd nanoparticles in SILP on CNF/SMF Inconel structured supports for the selective hydrogenation of acetylene in argon and in ethylene-rich streams. Two different imidazolium-based IL have been used, $[\mathrm{bmim}]\left[\mathrm{PF}_{6}\right]$ and $[\mathrm{bmimOH}]\left[\mathrm{Tf}_{2} \mathrm{~N}\right]$, to elucidate the influence of the IL on the catalytic properties. Furthermore, NMR spectroscopy was used to determine the solubility of the reactants in $[\mathrm{bmim}]\left[\mathrm{PF}_{6}\right]$ and the mass transfer from the gas phase to the catalytically active Pd nanoparticles.

\section{Experimental}

2.1. Materials. Sintered metal fibers Bekipor ST 20AL3 (Bekaert Fiber Technology, Belgium) made of Inconel 601 (alloy composition: $\mathrm{Ni}, 58-63 \%$; $\mathrm{Cr}, 21-25 \%$; $\mathrm{Al}, 1.4 \%$ ) in panel form (elementary filament diameter, $8 \mu \mathrm{m}$; panel thickness, $0.49 \mathrm{~mm}$; porosity, 81\%; weight, $750 \mathrm{~g} / \mathrm{m}^{2}$ ) were used as supports. Hydroxyl-functionalized butyl-3-methylimidazolium $\mathrm{N}$-bis(trifluoromethanesulfonyl)imidate $[\mathrm{bmimOH}]\left[\mathrm{TF}_{2} \mathrm{~N}\right]$ was synthesized as reported elsewhere; ${ }^{29}$ 1-butyl-3-methylimidazolium hexafluorophosphate, [bmim] $\left[\mathrm{PF}_{6}\right]$ (Alfa Aesar, 99\%), and 
other chemicals (Fluka, Aldrich, >98\%) and gases (Carbagas, $>99.99 \%$ ) were used as received.

2.2. Preparation of the Pd-Based SILP Catalysts. The $\mathrm{SMF}_{\text {Inconel }}$ was calcined at $650{ }^{\circ} \mathrm{C}$ for $3 \mathrm{~h}$ to remove contamination and enhance the surface roughness. The CNF coating was obtained by catalytic growth on $\mathrm{SMF}_{\text {Inconel }}$ as reported elsewhere ${ }^{28}$ and treated for $5 \mathrm{~min}$ in an ultrasonic bath with methanol to remove amorphous carbon. SILP catalysts were prepared by the impregnation of $\mathrm{CNF} / \mathrm{SMF}_{\text {Inconel }}$ supports with a solution containing acetone, $\mathrm{IL}\left([\mathrm{bmim}]\left[\mathrm{PF}_{6}\right]\right.$ or $\left.[\mathrm{bmimOH}]\left[\mathrm{TF}_{2} \mathrm{~N}\right]\right)$ and the catalyst precursor, $\mathrm{Pd}(\mathrm{acac})_{2}(4 \mathrm{wt} \%$ in $\mathrm{IL})$; the acetone volume was varied between 0.3 and $0.9 \mathrm{~mL}$ to obtain different IL loadings on the support. After evaporation of acetone, the catalyst contained 3-9 wt \% of IL phase and $0.05-0.11$ wt $\%$ of Pd. The catalyst was subsequently reduced to obtain $\mathrm{Pd}$ nanoparticles at $150{ }^{\circ} \mathrm{C}$ overnight at atmospheric pressure with $30 \% \mathrm{H}_{2}$ in $\mathrm{Ar}$ (total flow $150 \mathrm{~mL}(\mathrm{STP}) / \mathrm{min}$ ) for [bmim] $\left[\mathrm{PF}_{6}\right]$ and with $\mathrm{Ar}$ (flow $100 \mathrm{~mL}(\mathrm{STP}) / \mathrm{min}$ ) for $[\mathrm{bmimOH}]\left[\mathrm{TF}_{2} \mathrm{~N}\right]$ ).

2.3. Characterization of the Pd-Based SILP Catalysts. The $\mathrm{CNF} / \mathrm{SMF}$ Inconel $_{\text {surface morphology was studied by a scanning }}$ electron microscopy (SEM, Philips XL30 FEG) before and after IL phase deposition. The samples were placed in the microscope chamber without any pretreatment; SEM micrographs at $3500 \times$ and $15000 \times$ were taken with an accelerating voltage of $10 \mathrm{kV}$. The morphology of the Pd nanoparticles was characterized with a high-resolution transmission electron microscope (HR-TEM, Philips EM 430 ST) equipped with an energy dispersive X-ray (EDX) analyzer. The specimen sample for HR-TEM was prepared by removing the IL phase Pd nanoparticles supported on $\mathrm{CNF}$ from $\mathrm{SMF}_{\text {Inconel }}$ by ultrasonication (30 min in methanol). The sample was then deposited on a carbon film of a copper grid used in HRTEM. X-ray photoelectron spectroscopy (XPS) analysis of the catalyst was also carried out after the reduction of the precursor to $\mathrm{Pd}$ nanoparticle to estimate the $\mathrm{Pd}$ oxidation state using an Axis Ultra ESCA (Kratos, Manchester) with monochromated A1 K $\alpha$ radiation $(1486.6 \mathrm{eV})$.

2.4. Gas Solubility Measurements Using NMR Spectroscopy. The molar fraction of dissolved hydrocarbons $\left(\mathrm{C}_{2} \mathrm{H}_{2}\right.$, $\mathrm{C}_{2} \mathrm{H}_{4}, \mathrm{C}_{2} \mathrm{H}_{6}$ ) in [bmim] $\left[\mathrm{PF}_{6}\right]$ was determined in situ in a 10 mm sapphire NMR tube at a pressure of 1.0 atm at 25 and 75 ${ }^{\circ} \mathrm{C}$ to be as close as possible to the reaction conditions (see section 2.5). After bubbling and shaking for $1 \mathrm{~h},{ }^{13} \mathrm{C}$ and ${ }^{1} \mathrm{H}$ spectra were recordered on a Bruker DRX $400 \mathrm{MHz}$ NMR spectrometer. The integral of the ${ }^{13} \mathrm{C}$ or ${ }^{1} \mathrm{H}$ peaks in relation to the peak corresponding to the $\mathrm{CH}_{2}$ carbons of the butyl chain or the two 4, $5 \mathrm{CH}$ protons of the $[\mathrm{bmim}]\left[\mathrm{PF}_{6}\right]$ were determined using the NMRICMA2.8/MATLAB program (nonlinear leastsquares iterative fitting application for MATLAB).

2.5. Catalytic Activity/Selectivity during the Hydrogenation of Acetylene. The selective hydrogenation of acetylene (4 vol \% of acetylene, 4-30 vol \% of $\mathrm{H}_{2}$ in $\mathrm{Ar}$ ) was studied in a continuous fixed-bed tubular reactor at atmospheric pressure. Two slices of catalyst $\left(m_{\text {cat }} \sim 180 \mathrm{mg}\right.$ ) were placed perpendicularly to the gas flow in a stainless steel tubular reactor (internal diameter $12 \mathrm{~mm}$ ). At the reactor inlet, a bed of glass beads $(d=2 \mathrm{~mm})$ ensured good mixing and homogeneous temperature of the reactant mixture. A thermocouple inside the reactor, in contact with the catalyst bed, was used to monitor the temperature, which was kept constant using an external heating jacket. Mass flow controllers regulated the mixture to the reactor. The reaction temperature was set between 70 and $150{ }^{\circ} \mathrm{C}$. Products were analyzed online by gas chromatography (HP 6890) using a Carboxen 1010 (Supelco) capillary column, a flame ionizer, and a thermal conductivity detector. The catalytic activity was expressed in terms of specific reaction rate, $R\left[\mathrm{~mol} \cdot \mathrm{s}^{-1} \cdot \mathrm{g}_{\mathrm{Pd}}{ }^{-1}\right]$, calculated as the mol of acetylene converted per second and per gram of Pd on the catalyst. The selectivity toward ethylene was calculated as the molar ratio of ethylene obtained to acetylene converted; the same method was used for ethane, and the selectivity toward $\mathrm{C}_{x>2}$ was considered as the complement of the sum of the previous two.

The hydrogenation of acetylene was also carried out in ethylene-rich feed ( $2 \mathrm{vol} \%$ of acetylene, $40 \mathrm{vol} \%$ of ethylene, 10 vol $\%$ of $\mathrm{H}_{2}$ in Ar) using the same reactor setup and with the same catalytic systems. In this case, the catalytic activity was calculated as mentioned above (specific reaction rate, $R$ ). However, the true selectivity to ethylene was much more difficult to estimate, because it was not possible to distinguish between ethane directly converted from acetylene or produced through the ethylene hydrogenation. The approximated expressions frequently used in industrial plants do not take into account the direct acetylene hydrogenation to ethane, ${ }^{30}$ but an attempt to evaluate the selectivity from the mass balance on hydrogen is given in eqs 1 and 2:

$$
\begin{gathered}
C_{\mathrm{H}_{2, \text { in }}}-C_{\mathrm{H}_{2, \text { out }}}=\left(C_{\mathrm{C}_{2} \mathrm{H}_{2, \text { in }}}-C_{\mathrm{C}_{2} \mathrm{H}_{2, \text { out }}}\right) S_{\mathrm{C}_{2} \mathrm{H}_{4}}+2 C_{\mathrm{C}_{2} \mathrm{H}_{6, \text { out }}} \\
S_{\mathrm{C}_{2} \mathrm{H}_{4}}=\frac{\left(C_{\mathrm{H}_{2, \text { in }}}-C_{\mathrm{H}_{2, \text { out }}}\right)-2 C_{\mathrm{C}_{2} \mathrm{H}_{6, \text { out }}}}{C_{\mathrm{C}_{2} \mathrm{H}_{2, \text { in }}}-C_{\mathrm{C}_{2} \mathrm{H}_{2, \text { out }}}}
\end{gathered}
$$

Nevertheless, this is an approximation, because it assumes that a negligible amount of ethylene present in the feed is converted to ethane.

\section{Results and Discussion}

3.1. Characterization of the SILP catalysts. The morphology of the IL layer on the CNFs was probed by SEM for different IL loadings. Figure 1 shows that at low IL loading, it is possible to maintain the mesoporous structure of the CNF network (1-A), and on increasing the IL content, the CNFs are completely submerged by the IL (1-C). For slow reaction kinetics, the reactants have sufficient time to diffuse through a thick layer of IL embedding the catalytically active phase. Thus, the configuration of Figure 1-C (9 wt \% IL phase on CNF/ $\left.\mathrm{SMF}_{\text {Inconel }}\right)$ is preferred because it provides higher quantities of the active phase on the support while maintaining the homogeneity of the IL layer. ${ }^{27}$ For fast kinetics, as for acetylene hydrogenation, the morphology of Figure $1-\mathrm{A} / \mathrm{B}$ is better because it provides a higher surface area in contact with the gas phase and a thinner layer of IL in which the active $\mathrm{Pd}$ nanoparticles are embedded.

Figure 2 shows HR-TEM images of $\mathrm{Pd}$ nanoparticles (confirmed by in situ EDX) with a narrow size distribution. The reduction of $\mathrm{Pd}(\mathrm{acac})_{2}$ with $\mathrm{H}_{2}$ in $[\mathrm{bmim}]\left[\mathrm{PF}_{6}\right] / \mathrm{CNF} / \mathrm{SMF}_{\text {Inconel }}$ gave $\mathrm{Pd}$ particles with size distribution around $10 \mathrm{~nm}$ (deviation $<25 \%$ ), whereas merely heating $\mathrm{Pd}(\mathrm{acac})_{2}$ at $150{ }^{\circ} \mathrm{C}$ in $[$ bmimOH $]\left[\mathrm{Tf}_{2} \mathrm{~N}\right] / \mathrm{CNF} / \mathrm{SMF}_{\text {Inconel }}$ afforded $5 \mathrm{~nm}$ nanoparticles (deviation $<25 \%$ ). The $\mathrm{OH}$ functionality of the imidazolium moiety is probably responsible for the formation of $\operatorname{Pd}(0)$ nanoparticles via a redox reaction with the Pd (II) precursor. ${ }^{31}$ Similarly, the formation of $\mathrm{Au}(0)$ nanoparticles in IL phase without any external reducing agent has been reported. ${ }^{32}$ The apparent supramolecular structure of ILs inhibits agglomeration of the nanoparticles. ${ }^{20,33}$ It has recently been demonstrated that the IL anions influence the stabilization of metal nanoparticles and that the particle size can be controlled by the anion volume, ${ }^{21,34,35}$ which is not the case for the nanoparticles reported herein. In $[\mathrm{bmimOH}]\left[\mathrm{Tf}_{2} \mathrm{~N}\right]$, the hydroxyl group in the imdazolium cation is responsible for the formation of the 

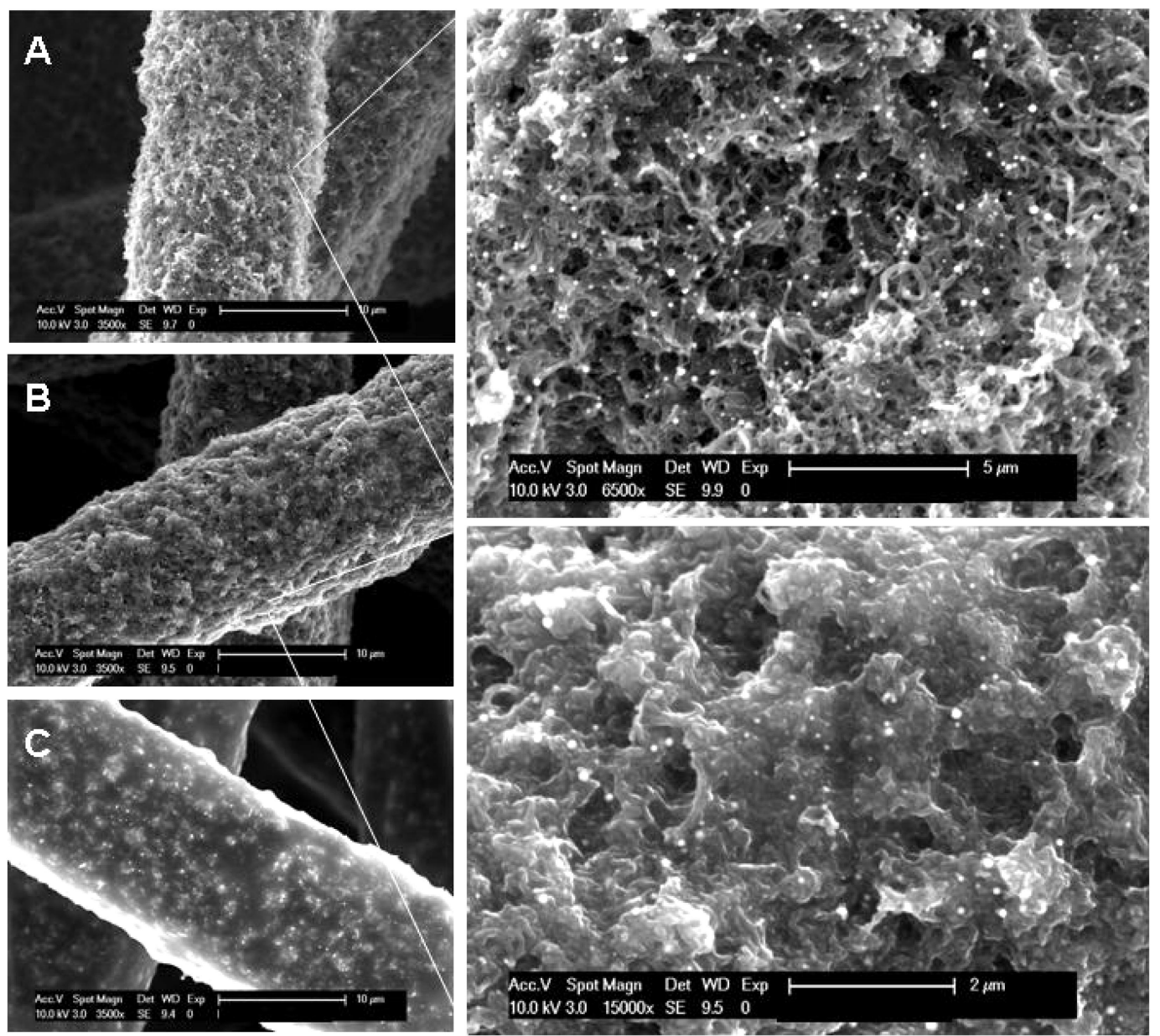

Figure 1. SEM micrographs of IL/CNF/SMF Inconel fibers with different IL loadings: (A) 3 wt \%, (B) 6 wt \%, (C) 9 wt $\%$.
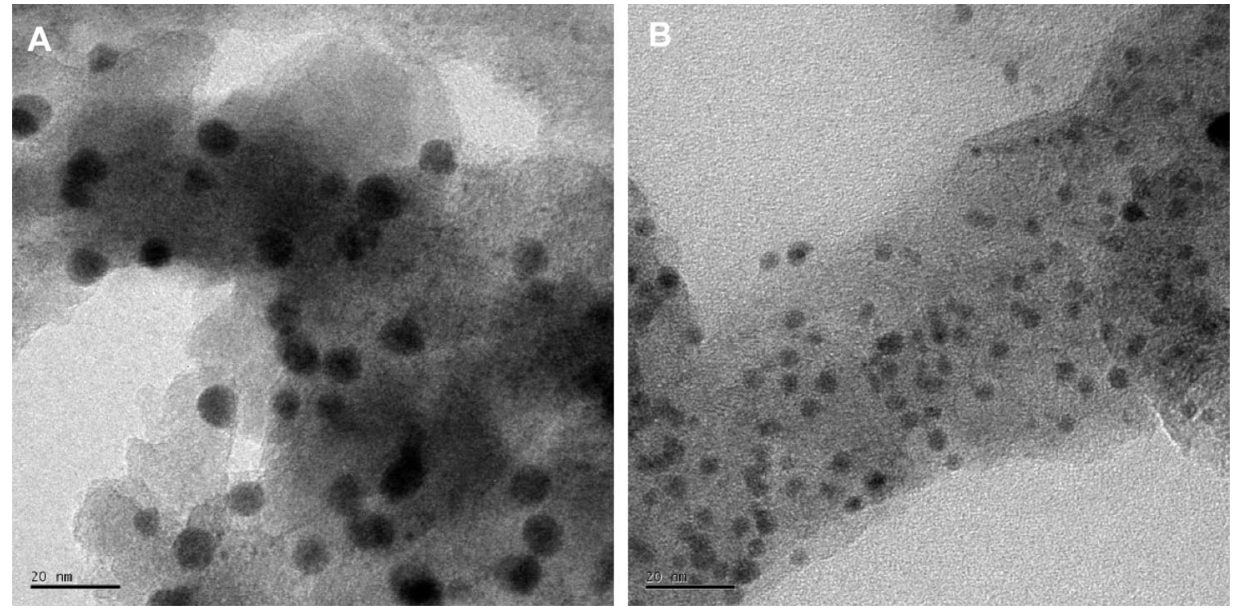

Figure 2. HRTEM micrographs: (A) $10 \mathrm{~nm}$ sized $\mathrm{Pd}$ nanoparticles formed in $[\mathrm{bmim}]\left[\mathrm{PF}_{6}\right] / \mathrm{CNF}_{\mathrm{SMF}} \mathrm{Snconel}_{\text {and }}(\mathrm{B}) 5 \mathrm{~nm}$ sized nanoparticles formed in $[\mathrm{bmimOH}]\left[\mathrm{Tf}_{2} \mathrm{~N}\right] / \mathrm{CNF} / \mathrm{SMF}_{\text {Inconel. }}$.

nanoparticles; thus, the order of the ionic layers surrounding the particle during its nucleation/growth changes, and the anion volume cannot be related to the particle size. As a result, smaller $\mathrm{Pd}$ nanoparticles than expected were formed.

The spectra obtained by XPS of the catalyst based on nanoparticles in $[\mathrm{bmim}]\left[\mathrm{PF}_{6}\right]$ were of poor signal-to-noise ratio in the $\mathrm{Pd} 3 \mathrm{~d}$ region due to the scarcity of Pd phase on the surface of the material. Nevertheless, it qualitatively revealed the presence of $\mathrm{Pd}(0)$ and $\mathrm{Pd}(\mathrm{II})$. For complete reduction of the $\mathrm{Pd}$ precursor, a 4-fold higher pressure of $\mathrm{H}_{2}$ would be required, ${ }^{13,20,36}$ and despite the presence of $\mathrm{H}_{2}$ during catalysis, no further reduction of the Pd precursor could be inferred. Indeed, the catalytic activity was stable and did not increase with time.

3.2. NMR Determination of the Reactant/Product Solubility in [bmim][PF 6 . NMR spectroscopy has previously been used to determine gas solubility in $[\mathrm{bmim}]\left[\mathrm{PF}_{6}\right] .{ }^{37,38}$ The solubility of the acetylene, ethylene, and ethane in $[\mathrm{bmim}]\left[\mathrm{PF}_{6}\right]$ was determined using this method (see section 2.4), and the results are presented in Table 1 as the measured gas concentrations in IL, where the errors were estimated from five parallel experiments. Following the general trend of gas solubility in liquids, the three gases were found to be less soluble as the 
TABLE 1: Measured Concentrations of Dissolved Gases under 0.101 $\mathrm{MPa}$ Pressure in $[\mathrm{bmim}]\left[\mathrm{PF}_{6}\right]$ at $25^{\circ} \mathrm{C}$ and at $7^{\circ} \mathrm{C}$

\begin{tabular}{lll}
\hline \multicolumn{1}{c}{ gas } & $\begin{array}{c}\text { mole fraction, } \\
x[-] \text { at } 25^{\circ} \mathrm{C}\end{array}$ & $\begin{array}{l}\text { mole fraction, } \\
x[-] \text { at } 75^{\circ} \mathrm{C}\end{array}$ \\
\hline acetylene & $(74 \pm 7) \times 10^{-3}$ & $(57 \pm 6) \times 10^{-3}$ \\
ethylene & $(6.5 \pm 2) \times 10^{-3}$ & $(2.8 \pm 1) \times 10^{-3}$ \\
ethane & $(3.5 \pm 1) \times 10^{-3}$ & $(1.6 \pm 1) \times 10^{-3}$
\end{tabular}

temperature increased, corresponding to an exothermic solvatation process. When comparing the concentration of three hydrocarbons dissolved in IL, the trend acetylene > ethylene $>$ ethane was observed, and the results for ethylene and ethane are consistent with available literature data. ${ }^{39-41}$ To the best of our knowledge, this is the first report on the solubility of acetylene in IL. Indeed, the amount of dissolved acetylene was found to be more than 10 times higher than that of ethylene, confirming that hydrocarbons with the same number of carbon atoms, but with increasing saturation, show lower solubility in [bmim $]\left[\mathrm{PF}_{6}\right]$. As previously observed by Dupont and coworkers $^{20}$ for the hydrogenation of 1,3 butadiene, the different solubility in IL of the unsaturated reactant and the intermediate (target) product has a positive effect on the selectivity when the reaction takes place in IL media. These results encouraged us to use the SILP Pd nanoparticles for the selective hydrogenation of acetylene.

3.3. Catalytic Activity for Acetylene Hydrogenation. The catalytic system was found active toward the acetylene hydrogenation in both ILs tested (see Table 2). Similar specific reaction rates were observed for IL-free $\mathrm{Pd}$ nanoparticles supported on $\mathrm{CNF} / \mathrm{SMF} \mathrm{Inconel}{ }^{27}$ but in contrast to the referenced catalyst, no formation of green oil was inferred: on Pd-SILP catalysts, acetylene was converted only to gaseous ethylene and ethane, confirmed by the molar balance from the GC analysis. The oligomerization of acetylene giving $\mathrm{C}_{x>2}$, which is known to strongly deactivate the catalyst, ${ }^{4,7,42}$ was not observed. Consequently, the activity and selectivity did not change significantly over $6 \mathrm{~h}$ on-stream, as shown in Figure 3. The IL layers probably control the access of the reagents to the $\mathrm{Pd}$ nanoparticles and hinder part of the surface, preventing the formation of active-site ensembles known to facilitate the formation of oligomers. ${ }^{43}$ Furthermore, both hydrogen and acetylene take part in the oligomerization, which is negligible without hydrogen. ${ }^{30}$ Due to the low solubility of hydrogen in $\mathrm{ILs}^{37}$ and to the hindered access of hydrogen to the $\mathrm{Pd}$ nanoparticle surface, the oligomerization of acetylene is reduced. Most likely, the supramolecular structures created by the IL around the particle promote the surface segregation into small sites, which also increases the selectivity to ethylene.

Since the catalyst did not show any deactivation, it was possible to reuse it for several runs, even after exposure to air. Indeed, it is known that the interaction of the IL with the metal surface enhances the stability of the nanoparticles. ${ }^{16,21}$ Two different ILs, $[\mathrm{bmim}]\left[\mathrm{PF}_{6}\right]$ and $[\mathrm{bmimOH}]\left[\mathrm{Tf}_{2} \mathrm{~N}\right]$, were employed, and Table 2 reports the observed activity. The activity is slightly higher in $[\mathrm{bmimOH}]\left[\mathrm{Tf}_{2} \mathrm{~N}\right]$ (entries 5 and 6), even though the nanoparticles are smaller ( $5 \mathrm{~nm}$ versus $10 \mathrm{~nm})$, being in the range where the activity is sensitive to particle size. ${ }^{9,10,44}$ The coordinating power of the IL anions, which form the first layer of the "protective shell" around the nanoparticle, influences the accessibility of the reactants to the particle, thus modifying its catalytic activity. The $\mathrm{Tf}_{2} \mathrm{~N}^{-}$anion is known to be less coordinating than $\mathrm{PF}_{6}{ }^{-},{ }^{45}$ and consequently, the nanoparticle surface is more accessible, and the catalytic activity is higher. ${ }^{19}$
Thus, the nature of the IL employed influences not only the size of nanoparticles formed but also their catalytic activity.

3.4. Mass Transfer Limitations. The presence of the IL layer on the support in which the Pd nanoparticles are embedded influences the observed activity as compared to the IL-free systems, since hydrogenation can be mass-transfer-controlled. ${ }^{46-48}$ To elucidate mass transfer, three different catalysts were prepared with increased amounts of $\mathrm{IL}\left(\mathrm{Pd}(\mathrm{acac})_{2} / \mathrm{IL}\right.$ ratio constant) and tested at $100{ }^{\circ} \mathrm{C}$ and atmospheric pressure. As shown in Figure 4, the specific reaction rate decreased with the increasing amount of IL, suggesting an influence of the mass transfer on the kinetics observed. To exclude the limitation of convective mass transport from the bulk gas phase to the IL phase, the total volumetric flow was varied between 50 and 500 $\mathrm{mL}(\mathrm{STP}) / \mathrm{min}$, consequently reducing the residence time on the catalyst and improving the external mass transfer. No major changes of the specific reaction rate were detected, indicating that the external mass transfer is negligible when compared to the internal diffusion term. The diffusion of gas species through the IL phase is linearly related to its solubility. As observed in other studies, ${ }^{37,39,49}$ the solubility of hydrogen in [bmim] $\left[\mathrm{PF}_{6}\right]$ is relatively low compared to hydrocarbons, and the Henry's constant at $25^{\circ} \mathrm{C}$ and 1 atm is 5380 bar, ${ }^{37}$ as compared to 173 \pm 17 bar and $355 \pm 36$ bar for ethylene and ethane, respectively. ${ }^{39}$ Despite the fact that the solubility of hydrogen increases with increasing temperature, ${ }^{49}$ it is highly probable that the reaction is limited by the diffusion of hydrogen through the IL film. This hypothesis was also confirmed by the higher activity of the $[\mathrm{bmimOH}]\left[\mathrm{Tf}_{2} \mathrm{~N}\right]$-based catalyst, due to the enhanced accessibility of the reactants to the nanoparticles (see above). Indeed, the solubility of hydrogen has been demonstrated to be higher in ILs with the $\mathrm{Tf}_{2} \mathrm{~N}^{-}$anion, regardless of the cation. ${ }^{37,50}$ The results in Table 2 suggest that the catalytic systems described herein operate in a mixed regime and the kinetics are influenced by the diffusion of hydrogen through the IL phase.

3.5. Catalyst Selectivity to Ethylene. The nature of the IL appears to influence the selectivity toward ethylene: at lower temperature $\left(70{ }^{\circ} \mathrm{C}\right)$, the nanoparticles immobilized in $\left[\right.$ bmimOH] $\left[\mathrm{Tf}_{2} \mathrm{~N}\right]$ are slightly more selective than those in $[\mathrm{bmim}]\left[\mathrm{PF}_{6}\right]$. At higher temperature $\left(150{ }^{\circ} \mathrm{C}\right)$, the selectivity to ethylene for both the ILs reaches the same value of $\sim 78 \%$. Indeed, the solubility of reagents and products depends on the nature of the IL. ${ }^{50}$ The difference in solubility between the reactant and the intermediate product in the IL phase (see section 3.2) can improve the selectivity toward the desired product, that is, ethylene. Consequently, working at a higher temperature results in a higher selectivity (Figure 5). Selectivity toward ethylene up to $85 \%$ was achieved at $150{ }^{\circ} \mathrm{C}$ with the nanoparticles in $[\mathrm{bmim}]\left[\mathrm{PF}_{6}\right]$. This is a significant increase as compared to the selectivity of $60 \%$ achieved with IL-free supported Pd nanoparticles ${ }^{28}$ and can be rationalized from the difference in the solubility. With increasing temperature, the hydrocarbon solubility decreases ${ }^{39}$ (as confirmed by NMR spectroscopy) while the hydrogen solubility increases. ${ }^{49}$ Since the reaction rate seems to be controlled by the hydrogen surface concentration, the overall specific reaction rate increases (Table 2). At the same time, the solubility of acetylene diminishes with increasing temperature, but to a lesser extent than ethylene and ethane. Therefore, the surface ethylene concentration is diminished (in favor of acetylene), inhibiting its consecutive hydrogenation to ethane. To verify this hypothesis, the selectivity to ethylene was monitored as the residence time was varied. The selectivity did not decrease at increased conversion, confirming that the consecutive route to ethane was negligible. 
TABLE 2: Characteristics of $\mathrm{Pd} / \mathrm{IL} / \mathrm{CNF} / \mathrm{SMF}_{\text {Inconel }}$ Catalysts Used for the Hydrogenation of Acetylene ${ }^{a}$

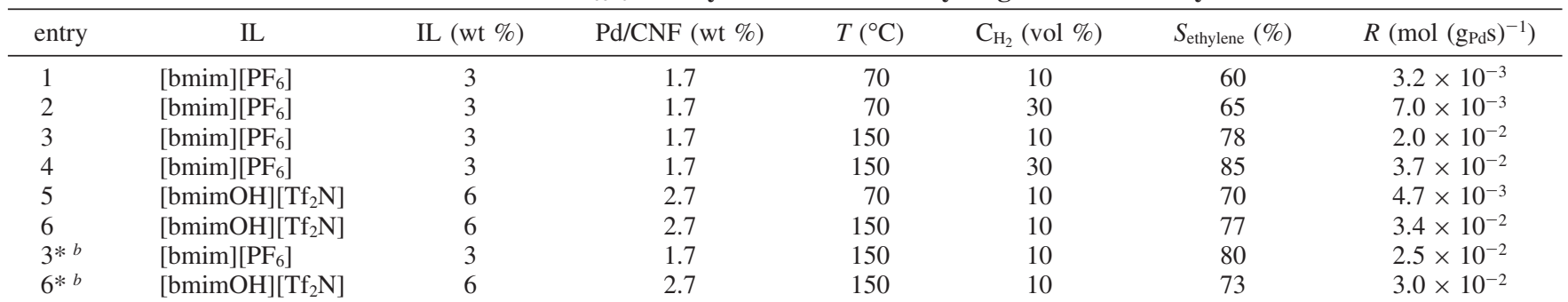

${ }^{a}$ Feed mixture: 4 vol $\% \mathrm{C}_{2} \mathrm{H}_{2}$ and $\mathrm{H}_{2}$ in Ar (total flow $250 \mathrm{~mL}$ (STP)/min). ${ }^{b}$ In $\mathrm{C}_{2} \mathrm{H}_{4}$ rich stream $\left(2 \% \mathrm{C}_{2} \mathrm{H}_{2}, 40 \% \mathrm{C}_{2} \mathrm{H}_{4}\right.$ and $\mathrm{H}_{2}$ in $\mathrm{Ar}, Q_{\text {tot }}=$ $150 \mathrm{~mL}(\mathrm{STP}) / \mathrm{min})$.

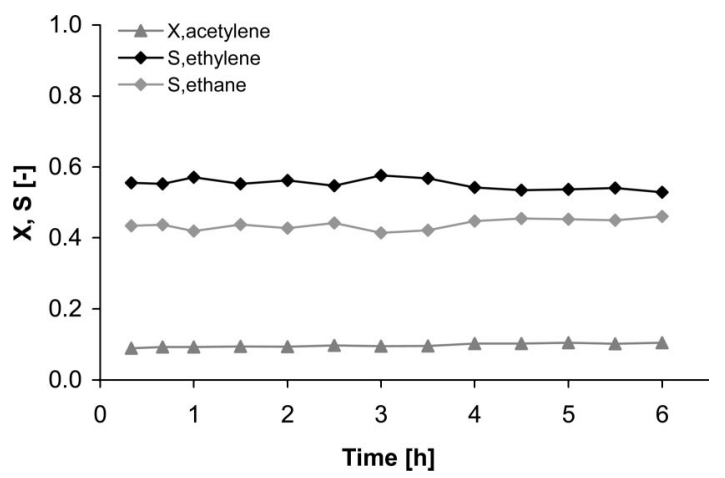

Figure 3. Conversion of acetylene and selectivity to ethylene and to ethane as functions of time on stream. Pd nanoparticles in $[\mathrm{bmim}]\left[\mathrm{PF}_{6}\right] /$ $\mathrm{CNF} / \mathrm{SMF}_{\text {Inconel }}$; reacting mixture $\mathrm{C}_{2} \mathrm{H}_{2} / \mathrm{H}_{2} / \mathrm{Ar}=4: 10: 86 ; Q_{\text {tot }}=250$ $\mathrm{mL}(\mathrm{STP}) / \mathrm{min} ; T=100^{\circ} \mathrm{C}$.

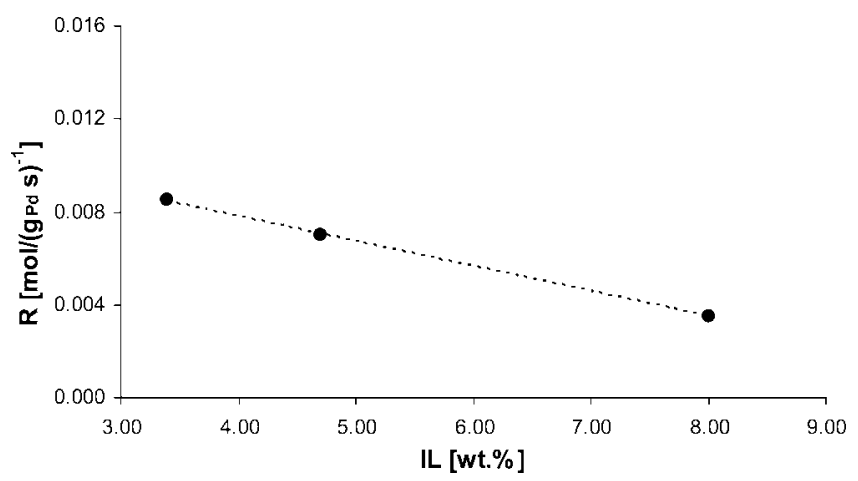

Figure 4. Specific reaction rate at different IL loadings, $\mathrm{Pd}$ nanoparticles in $[\mathrm{bmim}]\left[\mathrm{PF}_{6}\right] / \mathrm{CNF} / \mathrm{SMF}_{\text {Inconel}}$, reacting mixture $\mathrm{C}_{2} \mathrm{H}_{2} / \mathrm{H}_{2} / \mathrm{Ar}=$ $4: 30: 56 ; Q_{\text {tot }}=250 \mathrm{~mL}(\mathrm{STP}) / \mathrm{min} ; T=100^{\circ} \mathrm{C}$.

It is important to note that the conversion during these experiments always remained above $25 \%$, since the isothermal conditions within the catalytic bed could not be ensured at high conversions. The hydrogenation of acetylene to ethylene is a highly exothermic reaction $\left(\Delta H_{298 \mathrm{~K}}=-172 \mathrm{~kJ} / \mathrm{mol}\right){ }^{3}$ The adiabatic temperature rise of the system was estimated at $\sim 200$ $\mathrm{K}$. Therefore, hot-spot formation in the catalytic bed perturbing the kinetic measurements cannot be excluded. Further studies aimed at improved heat transfer within the reactor to better control the temperature by using a microreactor ${ }^{51}$ are in progress.

3.6. Selectivity to Ethylene during the Hydrogenation of Acetylene in Ethylene-Rich Streams. The major objectives for the hydrogenation treatment of industrial ethylene streams is to maximize the conversion of the acetylene impurities and to reach the target of $10 \mathrm{ppm}$ without loss of ethylene from the main stream. The catalysts were therefore tested for the hydrogenation of acetylene in an ethylene-rich feed. Due to the large excess of ethylene in the mixture, small changes of this component in the gas phase were difficult to detect, so the

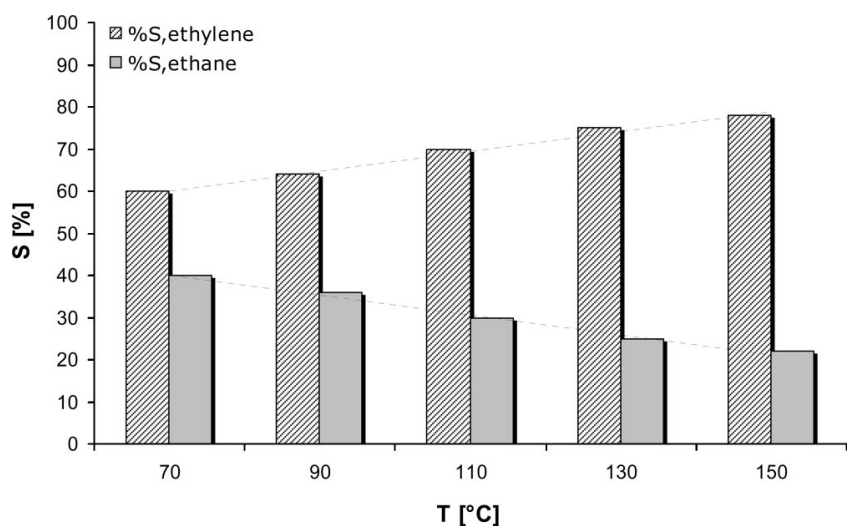

Figure 5. Dependence of the selectivity to ethylene and to ethane on the reaction temperature; conversion $\sim 10 \%$. Pd nanoparticles in $[\mathrm{bmim}]\left[\mathrm{PF}_{6}\right] / \mathrm{CNF} / \mathrm{SMF}_{\text {Inconel}}$; reacting mixture $\mathrm{C}_{2} \mathrm{H}_{2} / \mathrm{H}_{2} / \mathrm{Ar}=4: 10: 86$.

catalytic measurements were carried out at a higher residence time to have appreciable acetylene conversion (up to 80\%). The ethylene concentration was always found to be higher at the reactor outlet than at the inlet, confirming the preferential hydrogenation of acetylene compared to ethylene. The results summarized in Table 2 (entries $3^{*}$ and $6^{*}$ for the acetylene hydrogenation in an excess of ethylene) show that the selectivity to ethylene is close to those observed for the ethylene-free stream (entries 3 and 6). The difference is within the $\mathrm{GC}$ analysis error $(\leq 5 \%)$. Therefore, eq 2 used for the evaluation of the $S_{\mathrm{C}_{2}} \mathrm{H}_{4}$ selectivity (see section 2.5) is appropriate, since the losses of ethylene from the inlet feed, due to its hydrogenation to ethane, can be neglected. Indeed, if part of the ethane measured at the outlet was formed from the hydrogenation of ethylene present in the inlet, the selectivity calculated according to eq 2 would be underestimated. Thus, the catalytic system reported herein, which employs Pd nanoparticles immobilized in a SILP, is suitable for acetylene hydrogenation in ethylene-rich streams and is promising for industrial application in continuous-flow reactors.

\section{Conclusions}

Monodispersed Pd nanoparticles of 5 and $10 \mathrm{~nm}$ diameter were synthesized in SILPs on CNF/SMF Inconel $_{\text {and applied as }}$ structured catalysts for the selective hydrogenation of acetylene to ethylene in a continuous-flow tubular reactor. The SILP provided a favorable environment for the formation and the stabilization of Pd nanoparticles: $10 \mathrm{~nm}$ Pd particles were formed by $\mathrm{H}_{2}$ reduction of $\mathrm{Pd}(\mathrm{acac})_{2}$ in $[\mathrm{bmim}]\left[\mathrm{PF}_{6}\right]$ and $5 \mathrm{~nm}$ particles by simply heating $\mathrm{Pd}(\mathrm{acac})_{2}$ in $[\mathrm{bmimOH}]\left[\mathrm{Tf}_{2} \mathrm{~N}\right]$. The catalytic activity of the Pd nanoparticles in the SILP/CNF/SMF material was found to be close to the activity of IL-free nanoparticles supported on $\mathrm{CNF} / \mathrm{SMF}$, with an enormous gain in the selectiv- 
ity to gaseous products $\sim 100 \%$. Since no oligomerization (green oil formation) was observed, the catalyst demonstrated excellent long-term stability without any deactivation during $8 \mathrm{~h}$ onstream. This was attributed to the IL network surrounding the $\mathrm{Pd}$ nanoparticles ensuring active site separation. Under the reaction conditions applied (low $\mathrm{H}_{2}$ pressure), the reaction rate was found to be influenced by internal mass transfer through the IL film, where the diffusion of $\mathrm{H}_{2}$ is the rate-determining step. The lower solubility in the SILP $\left([\mathrm{bmim}]\left[\mathrm{PF}_{6}\right]\right)$ of ethylene compared to acetylene, as determined by NMR spectroscopy, was found to be advantageous for ethylene selectivity, hindering the consecutive hydrogenation of ethylene to ethane. As a result, a selectivity of $85 \%$ toward ethylene has been attained at 150 ${ }^{\circ} \mathrm{C}$, which remained constant during $8 \mathrm{~h}$ on stream.

The catalytic system was tested for the hydrogenation of acetylene-ethylene mixtures, thus approaching the industrial conditions for cracked hydrocarbon streams. The selectivity to ethylene maintained between 70 and $80 \%$, depending on the IL employed, and the losses of ethylene due to its hydrogenation were found to be negligible.

Acknowledgment. The authors thank Dr. Dongbin Zhao for the preparation of $[\mathrm{bmimOH}]\left[\mathrm{Tf}_{2} \mathrm{~N}\right]$, Mrs. Laub for the HRTEM and EDX, and Mr. N. Xanthopoulos for the XPS measurements. Financial support from the Swiss National Science Foundation is highly appreciated.

\section{References and Notes}

(1) Lam, W. K.; Lloyd, L. Oil Gas J. 1972, 27, 66.

(2) Derrien, M. L. Catalytic Hydrogenation; Elsevier: Amsterdam, 1986; Vol. 27.

(3) Bos, A. N. R.; Westerterp, K. R. Chem. Eng. Process. 1993, 32, 1.

(4) Borodzinski, A.; Cybulski, A. Appl. Catal., Aq 2000, 198, 51.

(5) Sarkany, A. React. Kinet. Catal. Lett. 2001, 74, 299.

(6) Sarkany, A.; Guczi, L.; Weiss, A. H. Appl. Catal. 1984, 10, 369.

(7) Sarkany, A.; Weiss, A. H.; Szilagyi, T.; Sandor, P.; Guczi, L. Appl. Catal. 1984, 12, 373.

(8) Boitiaux, J. P.; Cosyns, J.; Vasudevan, S. Appl. Catal. 1983, 6, 41.

(9) Borodzinski, A. Catal. Lett. 2001, 71, 169.

(10) Che, M.; Bennett, C. O. Adv. Catal. 1989, 36, 55. 133.

(11) Gigola, C. E.; Aduriz, H. R.; Bodnariuk, P. Appl. Catal. 1986, 27,

(12) Finke R. G. Metal nanoparticles: synthesis, characterization and application; Marcel Dekker: New York, 2002.

(13) Dupont, J.; Fonseca, G. S.; Umpierre, A. P.; Fichtner, P. F. P.; Teixeira, S. R. J. Am. Chem. Soc. 2002, 124, 4228.

(14) Fonseca, G. S.; Umpierre, A. P.; Fichtner, P. F. P.; Teixeira, S. R.; Dupont, J. Chem.-Eur. J. 2003, 9, 3263.

(15) Huang, J.; Jiang, T.; Gao, H. X.; Han, B. X.; Liu, Z. M.; Wu, W. Z.; Chang, Y. H.; Zhao, G. Y. Angew. Chem., Int. Ed. 2004, 43, 1397.

(16) Migowski, P.; Dupont, J. Chem.-Eur. J. 2007, 13, 32.

(17) Migowski, P.; Machado, G.; Texeira, S. R.; Alves, M. C. M.; Morais, J.; Traverse, A.; Dupont, J. Phys. Chem. Chem. Phys. 2007, 9 , 4814.
(18) Mikkola, J. P. T.; Virtanen, P. P.; Kordas, K.; Karhu, H.; Salmi, T. O. Appl. Catal., A 2007, 328, 68.

(19) Scheeren, C. W.; Machado, G.; Teixeira, S. R.; Morais, J.; Domingos, J. B.; Dupont, J. J. Phys. Chem. B 2006, 110, 13011.

(20) Umpierre, A. P.; Machado, G.; Fecher, G. H.; Morais, J.; Dupont, J. Adv. Synth. Catal. 2005, 347, 1404.

(21) Machado, G.; Scholten, J. D.; de Vargas, T.; Teixeira, S. R.; Ronchi, L. H.; Dupont, J. Int. J. Nanotechnol. 2007, 4, 541.

(22) Haumann, M.; Dentler, K.; Joni, J.; Riisager, A.; Wasserscheid, P. Adv. Synth. Catal. 2007, 349, 425.

(23) Mehnert, C. P.; Mozeleski, E. J.; Cook, R. A. Chem. Commun. 2002, 3010.

(24) Mikkola, J. P.; Virtanen, P.; Karhu, H.; Salmi, T.; Murzin, D. Y. Green Chem. 2006, 8, 197.

(25) Riisager, A.; Fehrmann, R.; Haumann, M.; Wasserscheid, P. Eur. J. Inorg. Chem. 2006, 695.

(26) Valkenberg, M. H.; de Castro, C.; Holderich, W. F. Green Chem. 2002, $4,88$.

(27) Ruta, M.; Yuranov, I.; Dyson, P. J.; Laurenczy, G.; Kiwi-Minsker, L. J. Catal. 2007, 247, 269.

(28) Tribolet, P.; Kiwi-Minsker, L. Catal. Today 2005, 102, 15.

(29) Branco, L. C.; Rosa, J. N.; Ramos, J. J. M.; Afonso, C. A. M. Chem.-Eur. J. 2002, 8, 3671.

(30) Battiston, G. C.; Dalloro, L.; Tauszik, G. R. Appl. Catal. 1982, 2,1 .

(31) Toshima N. Fine Particles: Synthesis, Characterization, and Mechanism of Growth; Marcel Dekker: New York, 2000; Vol. 92.

(32) Ren, L.; Meng, L.; Lu, Q.; Fei, F.; Dyson, P. J. J. Colloid Interface Sci. 2008, 323, 260 .

(33) Dupont, J. J. Braz. Chem. Soc. 2004, 15, 341.

(34) Redel, E.; Thomann, R.; Janiak, C. Inorg. Chem. 2008, 47, 14.

(35) Redel, E.; Thomann, R.; Janiak, C. Chem. Commun. 2008, 1789.

(36) Scheeren, C. W.; Machado, G.; Dupont, J.; Fichtner, P. F. P.; Texeira, S. R. Inorg. Chem. 2003, 42, 4738.

(37) Dyson, P. J.; Laurenczy, G.; Ohlin, C. A.; Vallance, J.; Welton, T. Chem. Commun. 2003, 2418.

(38) Ohlin, C. A.; Dyson, P. J.; Laurenczy, G. Chem. Commun. 2004, 1070

(39) Anthony, J. L.; Maginn, E. J.; Brennecke, J. F. J. Phys. Chem. B 2002, 106, 7315.

(40) Anthony, J. L.; Maginn, E. J.; Brennecke, J. F. Gas solubilities in 1-n-butyl-3-methylimidazolium hexafluorophosphate Ionic Liquids; ACS Symposium Series 818; American Chemical Society: Washington, DC, 2002; p 260.

(41) Camper, D.; Becker, C.; Koval, C.; Noble, R. Ind. Eng. Chem. Res. 2005, 44, 1928.

(42) Bond, G. C.; Dowden, D. A.; Mackenzie, N. Trans. Faraday Soc. 1958, 54, 1537.

(43) Borodzinski, A.; Bond, G. C. Catal. Rev. Sci. Eng. 2006, 48, 91. (44) Sarkany, A.; Weiss, A. H.; Guczi, L. J. Catal. 1986, 98, 550.

(45) Chiappe, C.; Pieraccini, D. J. Phys. Org. Chem. 2005, 18, 275.

(46) Chauvin, Y.; Mussmann, L.; Olivier, H. Angew. Chem., Int. Ed., Engl. 1996, 34, 2698.

(47) Hardacre, C.; Mullan, E. A.; Rooney, D. W.; Thompson, J. M.; Yablonsky, G. S. Chem. Eng. Sci. 2006, 61, 6995.

(48) Mikkola, J. P.; Warna, J.; Virtanen, P.; Salmi, T. Ind. Eng. Chem. Res. 2007, 46, 3932.

(49) Kumelan, J.; Kamps, A. P. S.; Tuma, D.; Maurer, G. J. Chem. Eng. Data 2006, 51, 11.

(50) Anthony, J. L.; Anderson, J. L.; Maginn, E. J.; Brennecke, J. F. J. Phys. Chem. B 2005, 109, 6366.

(51) Kiwi-Minsker, L.; Renken, A. Catal. Today 2005, 110, 2.

JP806603F 